\title{
Expanding the scope of electromagnetic navigation bronchoscopy-guided transbronchial biopsy and ablation with mobile 3D C-arm Machine Cios Spin ${ }^{\circledR}$-feasibility and challenges
}

\author{
Joyce W. Y. Chan ${ }^{1}$, Rainbow W. H. Lau ${ }^{1}$, Cheuk Man Chu' ${ }^{2}$ Calvin S. H. Ng ${ }^{1}$ \\ ${ }^{1}$ Division of Cardiothoracic Surgery, Department of Surgery, Prince of Wales Hospital, the Chinese University of Hong Kong, Hong Kong, China; \\ ${ }^{2}$ Department of Imaging and Interventional Radiology, Prince of Wales Hospital, the Chinese University of Hong Kong, Hong Kong, China \\ Correspondence to: Dr. Calvin S. H. Ng, MD, FRCS. Professor, Division of Cardiothoracic Surgery, Department of Surgery, The Chinese University \\ of Hong Kong, Prince of Wales Hospital, Hong Kong, China. Email: calvinng@surgery.cuhk.edu.hk.
}

Submitted Aug 08, 2021. Accepted for publication Sep 29, 2021.

doi: $10.21037 /$ tlcr-21-619

View this article at: https://dx.doi.org/10.21037/tlcr-21-619

Electromagnetic navigation bronchoscopy (ENB)-guided procedures are being increasingly popular, these include ENB biopsy of lung nodules, dye marking for subsequent surgical wedge biopsy $(1,2)$, implantation of fiducial marker $(3,4)$, and the promising novel technique of transbronchial lung nodule ablation under ENB and cone-beam CT (CBCT) guidance $(5,6)$. For more complicated cases involving peripheral small lesions requiring transbronchial access, real-time fluoroscopy and CBCT is required to improve accuracy and confirm needle placement within nodules, usually in the setting of hybrid theatre (7). For ENB thermal ablation, CT is indispensable for confirmation of ablation catheter position, and for evaluation of ablation success and margin determination. However, hybrid theatre with en suite fluoroscopy and CBCT is not readily available in many centres due to high set-up and maintenance costs, limiting the growth of ENB applications.

We read with interest the latest case report from Chen et al. on the use of mobile 3-dimensional (3D) C-arm-assisted transbronchial biopsy and ablation of lung nodules (8), which eliminates the need of a hybrid theatre. While the authors should be congratulated on their proof of feasibility of this technique, we would like to supplement with our own comparative case series using the same mobile $\mathrm{C}$-arm system and highlight the challenges faced and the importance of case selection.

The mobile C-arm model utilized is Cios $\operatorname{Spin}^{\circledR}$ by Siemens Healthineers, which is a compact system with built-in 3D CT reconstruction capabilities (9). The CT image quality is state-of-the-art due to Retina $3 \mathrm{D}$ scan technology, metal artifact reduction and iso-centric technology. CT scans can be performed by one rotation of gantry within 30 seconds and only require an extra few seconds to generate a $3 \mathrm{D}$ reconstruction with a large $3 \mathrm{D}$ volume resolution of $512 \times 512 \times 512$ pixels. Simultaneous display of 3 projections (axial, coronal, sagittal) and as a $3 \mathrm{D}$ rendering allows accurate assessment of ENB navigation success. Minor readjustments can be performed with builtin fluoroscopy screening.

We evaluated the feasibility of performing ENB procedures with Cios $\operatorname{Spin}^{\circledR}$ guidance by comparing the results with floor-mounted CBCT (syngo DynaCT ${ }^{\circledR}$ of Artis Zeego by Siemens Healthineers) (10) in our hybrid operating room. The series comprise of 10 cases between December 2020 and March 2021 and have been enrolled prospectively in our registry. Informed consent has been obtained from all patients. Five cases of ENB biopsy, 2 cases of ENB dye marking for subsequent surgery and 4 cases of ENB transbronchial microwave ablation were performed (Table 1). The mean maximal diameter of target lung nodules for biopsy was $30 \mathrm{~mm}$ (ranging from 12 to $67 \mathrm{~mm}$ ), while that for ablation was $15 \mathrm{~mm}$ (ranging from 9 to $23 \mathrm{~mm}$ ). Navigation success was $80 \%$, while diagnostic yield for biopsy was $80 \%$ (4 out of 5 cases). In general, Cios Spin ${ }^{\circledR}$ has comparable ease-of-use as floor-mounted CBCT machines and were able to identify most lung lesions, especially the larger and denser nodules (Figure 1A-1C).

Difficulty was met in two cases. Case 4 is an $8 \mathrm{~mm}$ right upper lobe ground glass nodule planned for dye marking followed by surgical wedge resection. However, upon 
Table 1 Nodule and procedural characteristics

\begin{tabular}{|c|c|c|c|c|c|c|c|c|c|c|c|}
\hline Case & Lobe & $\begin{array}{c}\text { Maximum } \\
\text { diameter of } \\
\text { nodule }(\mathrm{mm})\end{array}$ & $\begin{array}{l}\text { Suzuki } \\
\text { class }\end{array}$ & $\begin{array}{l}\text { Bronchus } \\
\text { sign }\end{array}$ & Biopsy & $\begin{array}{c}\text { Dye } \\
\text { marking }\end{array}$ & Ablation & $\begin{array}{c}\text { Procedure } \\
\text { success with } \\
\text { mobile C-arm }\end{array}$ & $\begin{array}{c}\text { Biopsy } \\
\text { pathology }\end{array}$ & Complications & Remarks \\
\hline 2 & LUL & 67 & 6 & + & + & & & $\mathrm{Y}$ & Adenocarcinoma & & \\
\hline 3 & RLL & 15 & 4 & - & & & + & $\mathrm{Y}$ & & & $\begin{array}{l}5 \mathrm{~mm} \text { minimum } \\
\text { ablation margin }\end{array}$ \\
\hline 4 & RUL & 8 & 2 & - & & + & & $\mathrm{N}$ & & & $\begin{array}{c}\text { Successful } \\
\text { resection. Final } \\
\text { pathology: AAH }\end{array}$ \\
\hline 5 & RLL & 9 & 4 & - & & + & & Y & & & $\begin{array}{l}\text { Successful } \\
\text { resection. Final } \\
\text { pathology: } \\
\text { adenocarcinoma }\end{array}$ \\
\hline 7 & LLL & 9 & 6 & - & & & + & Y & & & $\begin{array}{l}5 \mathrm{~mm} \text { minimum } \\
\text { ablation margin }\end{array}$ \\
\hline 8 & RLL & 12 & 6 & + & + & & & $Y$ & Hamartoma & & $\begin{array}{l}\text { Initial atelectasis } \\
\text { obscuring lesion, } \\
\text { later able to } \\
\text { visualize lesion after } \\
\text { lung recruitment }\end{array}$ \\
\hline 9 & RUL & 13 & 3 & - & & & + & $\mathrm{N}$ & & & $\begin{array}{l}4 \mathrm{~mm} \text { minimum } \\
\text { ablation margin }\end{array}$ \\
\hline
\end{tabular}

NEOM, no evidence of malignancy; AAH, atypical adenomatous hyperplasia; RUL, right upper lobe; RLL, right lower lobe; LUL, left upper lobe; LLL, left lower lobe.

the first Cios Spin ${ }^{\circledR}$ CT, the lesion (HU -530) was barely visible, while it was more easily visualized on the DynaCT $^{\circledR}$ image by floor-mounted CBCT (Figure 1D,1E). After ENB navigation towards the lesion and needle deployment, the lesion was too faint on CT images generated by Cios Spin ${ }^{\circledR}$ with the presence of metallic artefacts, but still visible on DynaCT ${ }^{\circledR}$. Therefore, subsequent dye marking was performed only with DynaCT ${ }^{\circledR}$ image guidance. Case 9 is a $13 \mathrm{~mm}$ ground glass nodule in the right upper lobe abutting fissure, that was planned for ENB microwave ablation. The lesion was visible on Cios Spin ${ }^{\circledR}$ CT, yet initial ENB navigation resulted in needle tip placed $1.5 \mathrm{~cm}$ lateral to the lesion due to absence of bronchus sign. In order to ablate the lesion with adequate margin, the needle tip needed to be re-deployed in closer proximity to the nodule with fine adjustments. The lesion was too faint to be visualized on fluoroscopy, and due to the lack of marking tools on Cios $\operatorname{Spin}^{\circledR}$, the subsequent procedure was performed with DynaCT $^{\circledR}$ only. The lesion was segmented and marked with i-Guide on DynaCT ${ }^{\circledR}$ allowing live augmented fluoroscopy (ability to overlay lesion segmentation on live fluoroscopy). Successful fine repositioning of needle tip followed by ablation was achieved.

By direct comparison of the mobile Cios $\operatorname{Spin}^{\circledR} \mathrm{CT}$ and the floor-mounted DynaCT ${ }^{\circledR}$ in hybrid operating room in these 10 cases, and with extensive experience in ENB biopsy and ablation using DynaCT ${ }^{\circledR}$ in our institute, we conclude that mobile $\mathrm{C}$-arm machines can provide good enough resolution for most cases. Learning curve is not steep and the interface is easy to familiarize. However, we 


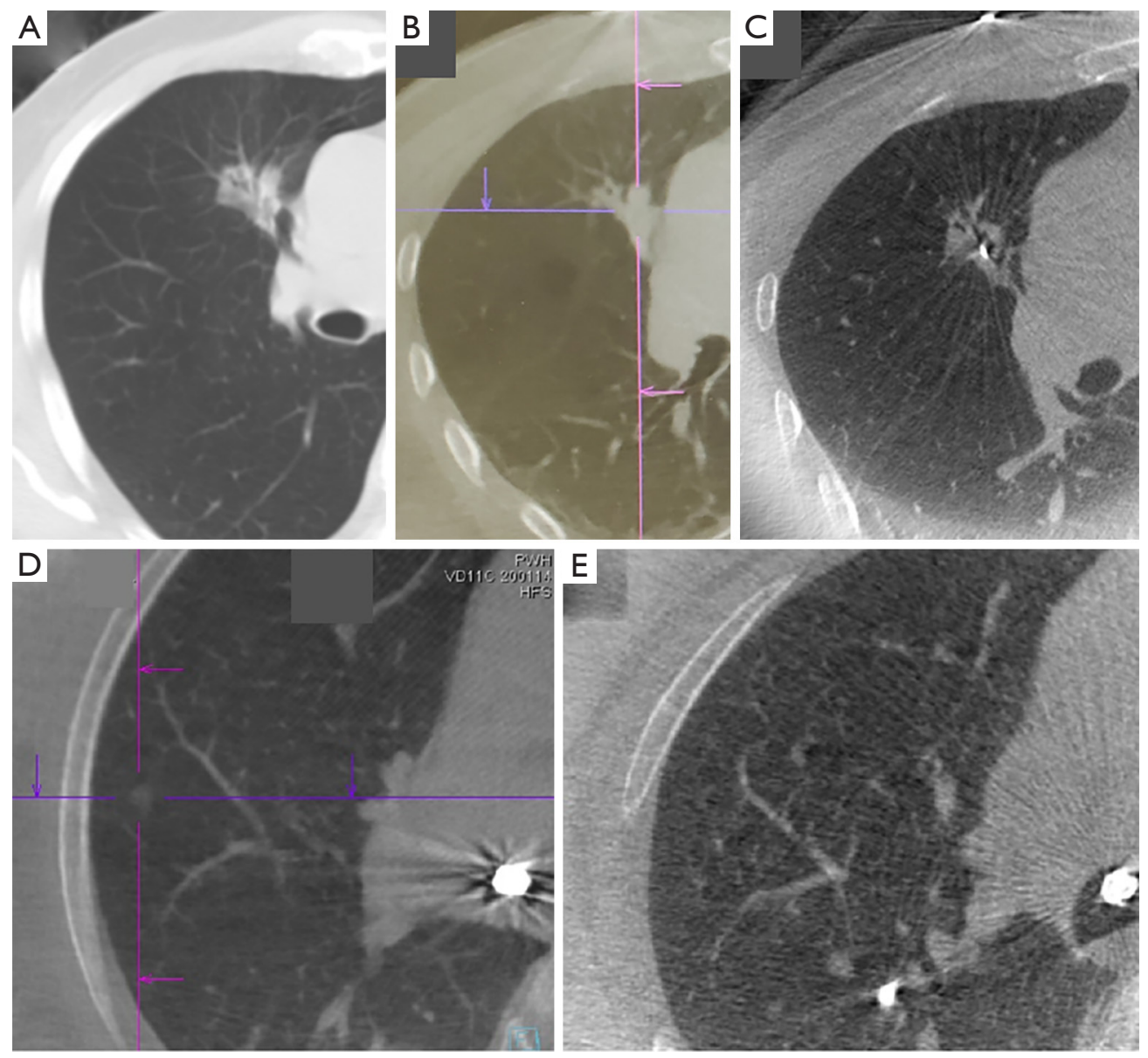

Figure 1 Comparison between the images taken by DynaCT ${ }^{\circledR}$ and Cios Spin ${ }^{\circledR}$. (A-C) A right upper lobe lung lesion on pre-operative plain fine-cut CT thorax (A), intraoperative $\operatorname{DynaCT}^{\circledR}$ (B), and intraoperative Cios Spin ${ }^{\circledR}$ CT (C). The lesion has mixed solid and ground glass opacities, and can be easily visualized on all three scans. (C) Also demonstrates needle tip within lesion for biopsy. (D,E) A faint and small $8 \mathrm{~mm}$ right upper lobe pure ground glass nodule (cross marked) on intraoperative DynaCT ${ }^{\circledR}$ (D) and Cios Spin ${ }^{\circledR}$ (E). Due to slight inferiority of image resolution on Cios Spin ${ }^{\circledR}$, the nodule is barely visualized in (E). The intersection of purple lines in (B,D) marks the target lesion.

do notice challenges in visualizing ground glass nodules of Suzuki type I to II, especially when there is surrounding atelectasis. The 3D volume of $16 \times 16 \times 16 \mathrm{~cm}$ in Cios Spin ${ }^{\circledR}$ is smaller than that of DynaCT ${ }^{\circledR}(19 \times 25 \times 25 \mathrm{~cm})$, thus extra attention is needed to focus the centre of rotation on the target lung nodule. The slightly longer time needed for image acquisition is not a problem for our cases as all are done under general anesthesia with inspiratory hold during scanning, but it can be a potential problem if procedure is done on awake or sedated patients who may not be able to perform a full inspiratory hold, leading to motion artefacts. To date, there is no marking tool available in the Cios Spin ${ }^{\circledR}$ system fluoroscopy, thus making it less ideal for cases which require fine adjustment after ENB navigation, usually in lesions that are more peripheral and lack bronchus sign. This is especially true for biopsy of small lesions where lesion puncture is absolutely necessary. Simple measurement tools are available on the Cios Spin ${ }^{\circledR}$ interface, but complicated mapping of a 3D ovoid ablation zone overlaying on the lesion is challenging.

In conclusion, ENB procedures performed under mobile $\mathrm{C}$-arm X-ray machine with 3D CT reconstruction capabilities is feasible, and relatively easy-to-use for those with prior experience of 3D image guidance. Nevertheless, case selection is important due to slight inferiority of image resolution. Our series is limited by its small number, thus formal comparative studies are needed to prove the accuracy of mobile $\mathrm{C}$-arm machines and to better delineate exact 
nodule selection criteria. Overall, mobile C-arm devices provide the much-needed solution to the relative paucity of hybrid operating rooms, and have high potential for the expansion of ENB services to meet the rising need of transbronchial diagnostic and therapeutic procedures.

\section{Acknowledgments}

Funding: None.

\section{Footnote}

Provenance and Peer Review: This article was a standard submission to the journal. The article has undergone external peer review.

Peer Review File: Available at https://dx.doi.org/10.21037/ tlcr-21-619

Conflicts of Interest: All authors have completed the ICMJE uniform disclosure form (available at https://dx.doi. org/10.21037/tlcr-21-619). CSHN is a consultant for Johnson and Johnson; Medtronic, USA; and Siemens Healthineers. RWHL is a consultant for Medtronic, USA; and Siemens Healthineers. The other authors have no conflicts of interest to declare.

Ethical Statement: The authors are accountable for all aspects of the work in ensuring that questions related to the accuracy or integrity of any part of the work are appropriately investigated and resolved.

Open Access Statement: This is an Open Access article distributed in accordance with the Creative Commons Attribution-NonCommercial-NoDerivs 4.0 International License (CC BY-NC-ND 4.0), which permits the noncommercial replication and distribution of the article with the strict proviso that no changes or edits are made and the original work is properly cited (including links to both the formal publication through the relevant DOI and the license). See: https://creativecommons.org/licenses/by-nc-nd/4.0/.

\section{References}

1. Ng CSH, Chu CM, Lo CK, Lau RWH. Hybrid operating room Dyna-computed tomography combined imageguided electromagnetic navigation bronchoscopy dye marking and hookwire localization video-assisted thoracic surgery metastasectomy. Interact Cardiovasc Thorac Surg 2018;26:338-40.

2. $\mathrm{Ng} \mathrm{CSH}$, Zhao Z, Long $\mathrm{H}$, et al. Electromagnetic Navigation Bronchoscopy Triple Contrast Dye Marking for Lung Nodule Localization. Thorac Cardiovasc Surg 2020;68:253-5.

3. Bowling MR, Folch EE, Khandhar SJ, et al. Fiducial marker placement with electromagnetic navigation bronchoscopy: a subgroup analysis of the prospective, multicenter NAVIGATE study. Ther Adv Respir Dis 2019;13:1753466619841234.

4. Chan JWY, Lau RWH, Ng CSH. Electromagnetic navigation bronchoscopy fiducial marker margin identification plus triple dye for complete lung nodule resection. JTCVS Tech 2020;3:329-33.

5. Chan JWY, Lau RWH, Ngai JCL, et al. Transbronchial microwave ablation of lung nodules with electromagnetic navigation bronchoscopy guidance-a novel technique and initial experience with 30 cases. Transl Lung Cancer Res 2021;10:1608-22.

6. Yuan HB, Wang XY, Sun JY, et al. Flexible bronchoscopyguided microwave ablation in peripheral porcine lung: a new minimally-invasive ablation. Transl Lung Cancer Res 2019;8:787-96.

7. Ng CS, Yu SC, Lau RW, et al. Hybrid DynaCT-guided electromagnetic navigational bronchoscopic biopsy†. Eur J Cardiothorac Surg 2016;49 Suppl 1:i87-8.

8. Chen J, Xie F, Zheng X, et al. Mobile 3-dimensional (3D) C-arm system-assisted transbronchial biopsy and ablation for ground-glass opacity pulmonary nodules: a case report. Transl Lung Cancer Res 2021;10:3312-9.

9. Cios spin ${ }^{\circledR}$ by Siemens Healthineers. Available online: https://www.siemens-healthineers.com/surgical-c-armsand-navigation/mobile-c-arms/cios-spin

10. Syngo DynaCT® of Artis Zeego by Siemens Healthineers. Available online: https://www.siemens-healthineers. com/angio/options-and-upgrades/clinical-softwareapplications/syngo-dynact

Cite this article as: Chan JWY, Lau RWH, Chu CM, Ng CSH. Expanding the scope of electromagnetic navigation bronchoscopy-guided transbronchial biopsy and ablation with mobile 3D C-arm Machine Cios Spin ${ }^{\circledR}$-feasibility and challenges. Transl Lung Cancer Res 2021;10(10):4043-4046. doi: 10.21037/tlcr-21-619 